\title{
Shoulder injuries in provincial male fast bowlers - predisposing factors
}

\author{
K D Aginsky ${ }^{1}$ (BA (Hons) Biokinetics) ${ }^{1}$ \\ L Lategan ${ }^{1}$ (DPhil) ${ }^{1}$ \\ R A Stretch ${ }^{2}$ (DPhil)
}

${ }^{1}$ Rand Afrikaans University, Johannesburg

${ }^{2}$ Sport Bureau, University of Port Elizabeth

\begin{abstract}
Objectives. To investigate the relationship between shoulder flexibility and isokinetic strength as possible factors that may predispose provincial fast bowlers to shoulder injuries.

Design. Twenty-one players, 12 of whom had no history of shoulder injuries and 9 of whom had experienced a shoulder injury to the bowling arm, were assessed for shoulder strength using a Cybex Norm isokinetic dynamometer. Absolute and relative peak torque measures were obtained at isokinetic speeds of $90 \%$ and $180 \%$ s, with both concentric and eccentric contractions performed. Shoulder flexibility was tested using a Leighton Flexometer in both internal and external shoulder rotation. The players were classified into a front-on $(N=7)$, semi front-on $(N=7)$ or side-on $(N=7)$ bowling action from video footage recorded after a bowling trial in the nets.

Results. Shoulder injuries were more common in fast bowlers with a front-on action $(N=5)$ than the bowlers with a side-on $(N=2)$ or semi front-on $(N=2)$ action. Sixteen of the 21 fast bowlers showed low stability ratios compared with gravity corrected functional ratios, indicating an imbalance and the presence of possible dysfunction. The injured group of fast bowlers showed higher concentric weight-normalised torque values for internal rotation at the higher velocity $\left(180^{\circ} / \mathrm{s}\right)(65.20 \pm 10.03$ vs. $45.91 \pm 10.26 \mathrm{Nm}_{\mathrm{kg}} \mathrm{kg}^{-1} p$ < 0.009: injured vs. uninjured), which would suggest greater instability when compared with the uninjured players. This imbalance could indicate the presence of a predisposition to impingement syn-
\end{abstract}

\section{CORRESPONDENCE:}

\section{R A Stretch}

University of Port Elizabeth

PO Box 1600

Port Elizabeth

Tel: 041-504 2584

Fax: 041-583 2605

E-mail: Richard.Stretch@upe.ac.za drome in the injured subjects. There was an increase in the external rotation ranges of movement for both groups, indicating a degree of hypermobility in both groups. The results indicate that the presence of possible dysfunction in the shoulder rotators, combined with a front-on bowling action and external rotation hypermobility, are possible predisposing factors for chronic shoulder injuries in cricket fast bowlers.

\section{Introduction}

The shoulder complex consists of 5 articulations, the glenohumeral, sternoclavicular, coracoclavicular, acromioclavicular and scapulothoracic joints, making it the most complex joint in the human body. ${ }^{1,10,15}$ One of the most important joints used in shoulder movements is the glenohumeral joint, which lacks bony stability and sacrifices the stability for increased mobility. ${ }^{17,13}$ Stability in the glenohumeral joint is provided by the glenohumeral ligaments, glenoid labrum, shoulder capsule and by the rotator cuff muscles. The external rotator strength has been reported to be around $65 \%$ of internal rotator strength. ${ }^{17}$

During bowling in cricket, the internal shoulder rotators are involved in the acceleration phase of the arm through concentric contractions, while the external rotators are involved during the deceleration phase. ${ }^{4}$ The nature of fast bowling requires the arm to be rotated at around $6000^{\circ} . \mathrm{s}^{-1}$, placing great demands on the shoulder's integrity. ${ }^{7}$ In addition to the technical skills required to perform, cricketers also need to possess a high level of fitness, thus making them susceptible to overuse injuries as a result of repetitive training. ${ }^{5}$

The upper extremities account for $25 \%$ and $22 \%$ of injuries in schoolboy ${ }^{19}$ and provincial ${ }^{20}$ cricket players, respectively. However, fast bowlers have a high incidence of shoulder injuries, with fast bowlers sustaining $42 \%$ of the upper extremity injuries to cricketers. ${ }^{5}$ Injuries in fast bowlers may be caused by a number of factors, such as postural defects, poor bowling technique, inadequate physical or physiological attributes, as well as high physical demands. ${ }^{19}$ Further, during a match many bowlers are placed to field in the outfield and thus have a tendency to develop 'thrower's arm' and other injuries. ${ }^{19}$ Fast bowlers with a front-on bowling action are more susceptible to an injury of the shoulder. ${ }^{10}$

The presence of an imbalance between the agonist and antagonist groups is one of the major risk factors for devel- 
oping shoulder injuries such as dislocation and impingement, ${ }^{16}$ with deficiency in the external rotator strength possibly resulting in an injury. ${ }^{7}$ Thus, the aim of the study was to investigate the relationship between shoulder flexibility and isokinetic strength as possible factors predisposing a male provincial fast bowler to shoulder injuries. The findings would assist in a better understanding of the risk factors for shoulder injury in an elite fast bowler, thus suggesting methods for reducing the incidence of injury and contributing to a prolonged career with fewer shoulder problems.

\section{Methods}

The subjects consisted of 21 male right-arm fast bowlers who had all represented their province at either under-19, provincial academy, under-23, provincial B or provincial A level. Their age ranged from 17 to 36 years, with a mean age of 22.4 years. The subjects were randomly chosen from those who were within travelling distance of the test centre.

Prior to testing the test protocol was explained to each subject, the informed consent form was signed, biographical data, which included personal information, level of participation, training schedules, injury history specifically relating to the shoulder, and body composition and somatotype data, were obtained. The subjects were then instructed to warm up for 5 minutes on a rowing ergometer and to stretch their shoulder complex before being tested isokinetically.

Isokinetic shoulder testing was performed on the Cybex Norm Isokinetic Dynamometer (Cybex International, Inc., Lumex Inc., Chattanooga, USA). Each subject was positioned on the Cybex to assess the internal and external shoulder rotation of the bowling arm, according to the manufacturers' guidelines. The arm was abducted at $90^{\circ}$ with $90^{\circ}$ of elbow flexion and secured by a velcro strap in a Vshaped padded trough attached to the lever arm base. The lever arm handle was then brought to a position where the grasp was comfortable, with the wrist maintaining a neutral position. The range of motion for shoulder rotation was set identically for everyone unless any discomfort was experienced. The test velocities were set at $90^{\circ} . \mathrm{s}^{-1}$ and $180^{\circ} . \mathrm{s}^{-1}$. Both concentric and eccentric muscle actions were tested and gravity corrected. The order of testing proceeded from the slow speed to the fast speed and was standardised for all subjects. Each subject was given the opportunity to familiarise himself with the dynamometer prior to the testing. A 1-minute rest period was observed between trials and test repetitions. Cybex Norm soft motion stops were placed at a range of movement (ROM) $150^{\circ}$ apart. The test protocol was standardised for all subjects.

After a sufficient rest period following the Cybex testing, flexibility was tested using a Leighton Flexometer. ${ }^{15}$ Internal rotation was assessed passively in a supine position with the elbow flexed at $90^{\circ}$ and the arm abducted at $90^{\circ}$. Rotation was measured up to a point where the athlete started to complain of pain or the humeral head began to protrude anteriorly, or no further ROM could be acquired. ${ }^{11}$

External rotation was also assessed passively in the same position. The same criteria were used for endpoints; however, extension of the thoracic spine was used as an endpoint and not humeral head protrusion.
In order to determine the classification of the bowling action each bowler was videotaped from the front, side and back. An expert coach was asked to classify each fast bowler's action into one of 3 actions. ${ }^{9}$ The side-on action requires a relatively slow run-up with the shoulders and hips pointing down the pitch to the wickets at the batsman's end at the time of back-foot placement in the delivery stride. The front-on action requires a faster run-up with a more openchest position at back-foot placement, with the shoulders and hips pointing towards third slip. The semi-front-on technique is based on the same principles as the above, with the alignment of the hips and shoulders pointing between the wickets at the batsman's end and third slip.

The statistical service (RAU) Statcon was used to compute single variable statistics, including means, standard deviations, minimums, maximums and level of significance. The $0.01 \%$ level of significance was used for all tests.

\section{Results}

The bowlers were classified as front-on $(N=7)$, side-on $(N=7)$ and semi-front-on $(N=7)$. Of these, 12 had not sustained a shoulder injury to their bowling arm, while the other 9 had sustained a chronic shoulder injury to their bowling arm. The results revealed that 5 of the 7 bowlers with a front-on technique had chronic shoulder injuries. Bowlers with the sideon and semi front-on bowling techniques reported 2 injuries each, with 1 of these injuries being a chronic shoulder injury.

The absolute concentric and eccentric torque measured at $90^{\circ} . \mathrm{s}^{-1}$ and $180^{\circ} . \mathrm{s}^{-1}$ for internal shoulder rotation was not different between the injured and uninjured groups. However, when the concentric internal rotation was weight-normalised, the injured subjects had a higher torque at $180^{\circ} . \mathrm{s}^{-1}(65.20 \pm$ 10.30 versus $45.91 \pm 10.26$; injured versus uninjured; $p=0.009$ ) (Table I).

The peak torque values of shoulder external rotation showed no significant difference between the injured and uninjured groups and within groups between the velocities (Table II). The absolute torque ratios between the injured

\begin{tabular}{|c|c|c|c|c|c|}
\hline & \multicolumn{2}{|c|}{ Injured $(N=9)$} & \multicolumn{2}{|c|}{ Uninjured $(N=12)$} & \multirow[b]{2}{*}{$P$-value } \\
\hline & Mean & SD & Mean & $\overline{S D}$ & \\
\hline \multicolumn{6}{|c|}{$\begin{array}{l}\text { Absolute concentric } \\
(\mathrm{Nm})\end{array}$} \\
\hline $90^{\circ}$ & 44.50 & 11.05 & 40.67 & 10.64 & 0.464 \\
\hline $180^{\circ}$ & 37.88 & 11.42 & 36.82 & 9.65 & 0.827 \\
\hline \multicolumn{6}{|c|}{$\begin{array}{l}\text { Absolute eccentric } \\
(\mathrm{Nm})\end{array}$} \\
\hline $90^{\circ}$ & -52.50 & 13.64 & -45.08 & 11.35 & 0.225 \\
\hline $180^{\circ}$ & -46.50 & 7.75 & -44.55 & 8.91 & 0.617 \\
\hline \multicolumn{6}{|c|}{$\begin{array}{l}\text { Normalised concentric } \\
(\mathrm{Nm} / \mathrm{kg})\end{array}$} \\
\hline $90^{\circ}$ & 51.94 & 11.39 & 51.83 & 11.97 & 0.984 \\
\hline $180^{\circ}$ & $65.20^{*}$ & 10.03 & 45.91 & 10.26 & 0.009 \\
\hline \multicolumn{6}{|c|}{$\begin{array}{l}\text { Normalised eccentric } \\
(\mathrm{Nm} / \mathrm{kg})\end{array}$} \\
\hline $90^{\circ}$ & 44.11 & 10.91 & 54.67 & 13.31 & 0.069 \\
\hline $180^{\circ}$ & 57.69 & 9.67 & 53.55 & 8.24 & 0.344 \\
\hline
\end{tabular}


and uninjured subjects for external and internal shoulder rotation showed no significant differences (Table III). However, the results for some subjects showed a muscle imbalance at both speeds, possibly predisposing them to injuries. All of the subjects except 5 had very low ratios. Due to eccentric values increasing with velocity, the ratio value should also increase. However, only a minor increase was shown in the results.

TABLE II. Torque values for external shoulder rotation at angular velocities of $90^{\circ}$ and $180^{\circ}$

\begin{tabular}{|c|c|c|c|c|c|}
\hline & \multicolumn{2}{|c|}{ Injured $(N=9)$} & \multicolumn{2}{|c|}{ Uninjured $(N=12)$} & \multirow[b]{2}{*}{$P$-value } \\
\hline & Mean & SD & Mean & SD & \\
\hline \multicolumn{6}{|c|}{$\begin{array}{l}\text { Absolute concentric } \\
(\mathrm{Nm})\end{array}$} \\
\hline $90^{\circ}$ & 34.25 & 11.26 & 31.33 & 7.84 & 0.537 \\
\hline $180^{\circ}$ & 29.50 & 9.49 & 27.91 & 6.61 & 0.691 \\
\hline \multicolumn{6}{|c|}{$\begin{array}{l}\text { Absolute eccentric } \\
(\mathrm{Nm})\end{array}$} \\
\hline $90^{\circ}$ & -44.63 & 11.02 & -40.24 & 7.37 & 0.363 \\
\hline $180^{\circ}$ & -42.38 & 10.81 & -38.00 & 5.93 & 0.324 \\
\hline \multicolumn{6}{|c|}{$\begin{array}{l}\text { Normalised concentric } \\
(\mathrm{Nm} / \mathrm{kg})\end{array}$} \\
\hline $90^{\circ}$ & 36.59 & 6.90 & 39.58 & 6.95 & 0.359 \\
\hline $180^{\circ}$ & 30.81 & 4.77 & 35.00 & 6.72 & 0.131 \\
\hline \multicolumn{6}{|c|}{$\begin{array}{l}\text { Normalised eccentric } \\
(\mathrm{Nm} / \mathrm{kg})\end{array}$} \\
\hline $90^{\circ}$ & 52.23 & 11.33 & 51.83 & 7.91 & 0.933 \\
\hline $180^{\circ}$ & 49.32 & 10.53 & 47.82 & 5.96 & 0.723 \\
\hline
\end{tabular}

TABLE III. Torque ratios for external and internal shoulder rotation at angular velocities of $90^{\circ}$ and $180^{\circ}$

\begin{tabular}{|c|c|c|c|c|c|}
\hline & \multicolumn{2}{|c|}{ Injured $(N=9)$} & \multicolumn{2}{|c|}{$\begin{array}{l}\text { Uninjured } \\
(N=12)\end{array}$} & \multirow[b]{2}{*}{$P$-value } \\
\hline & Mean & SD & Mean & SD & \\
\hline \multicolumn{6}{|c|}{$\begin{array}{l}\text { Absolute concentric } \\
\text { ratio }\end{array}$} \\
\hline $90^{\circ}$ & 72.13 & 15.92 & 78.58 & 12.83 & 0.356 \\
\hline $180^{\circ}$ & 73.88 & 17.68 & 78.18 & 13.17 & 0.571 \\
\hline \multicolumn{6}{|c|}{$\begin{array}{l}\text { Absolute eccentric } \\
\text { ratio }\end{array}$} \\
\hline $90^{\circ}$ & 103.63 & 28.11 & 104.17 & 23.74 & 0.965 \\
\hline $180^{\circ}$ & 117.38 & 36.74 & 107.64 & 23.38 & 0.523 \\
\hline
\end{tabular}

The results for the internal and external shoulder rotation flexibility of the injured and uninjured fast bowlers showed no significant difference between the groups (Table IV). There was an increase in the external rotation ranges of movement for both groups, indicating a degree of hypermobility in both groups. ${ }^{14}$

\section{Discussion}

The isokinetic strength characteristics of the internal/external rotator shoulder muscles, shoulder flexibility and bowling action of provincial fast bowlers are presented, with the principal finding indicating the relationship between these variables and the incidence of chronic shoulder injury in the bowling arm.
TABLE IV. Internal and external shoulder rotation flexibility $\left(^{\circ}\right)$

\begin{tabular}{|c|c|c|c|c|c|}
\hline & \multicolumn{2}{|c|}{ Injured $(N=9)$} & \multicolumn{2}{|c|}{ Uninjured $(N=12)$} & \multirow[b]{2}{*}{$P$-value } \\
\hline & Mean & SD & Mean & SD & \\
\hline Internal rotation & 84.00 & 10.77 & 89.75 & 17.26 & 0.361 \\
\hline External rotation & 116.22 & 10.26 & 116.83 & 7.91 & 0.884 \\
\hline
\end{tabular}

Although the sample size is very small, the results support previous research that shoulder injuries are more common in fast bowlers with a front-on action than bowlers with a side-on or semi front-on action. ${ }^{10}$ In the side-on action the ball velocity is generated by contributions from the run-up (20\%), leg action and hip rotation (24\%), trunk and shoulder rotation (11\%), arm $(41 \%)$ and hand and wrist $(5 \%)$. Although no research data are available on the contribution of various body segments to the ball velocity for the front-on action, the front-on bowling action requires a faster run-up

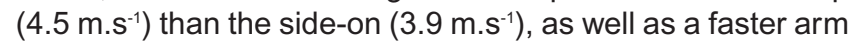
action. ${ }^{9}$ This faster arm action places more stress on the shoulder joint, predisposing these bowlers to shoulder injuries.

During the bowling action's acceleration phase, the external rotators are contracted eccentrically in order to decelerate and control the arm and any external shoulder rotation weakness could contribute to impingement syndrome. ${ }^{17}$ At $180^{\circ} . \mathrm{s}^{-1}$ the uninjured group showed greater concentric and eccentric weight-normalised peak torque values for internal rotation than external rotation. The greater relative strength of the internal rotators compared with the external rotators, would indicate a decreased deceleration of internal rotation resulting in migration of the humeral head and thus a decrease in the subacromial space causing impingement of the rotator cuff tendon. Thus fast bowlers should be advised to strengthen their external rotators to about $66 \%$ and $100 \%$ of the internal rotator concentric and eccentric strength, respectively. ${ }^{3}$

The fast bowler needs to decelerate the arm effectively from $6000^{\circ} . \mathrm{s}^{-1}$, resulting in an increase in the peak torque forces. ${ }^{2,4}$ Eccentric external rotation showed a decrease in peak torque as the velocity increased. This is not congruent with the velocity-curve graph and could predispose the players to injury as this may cause the prime movers (anterior deltoid and pectoralis major) to superiorly translate the humeral head into the subacromial space, resulting in rotator cuff impingement. $^{3}$

The eccentric external/concentric internal rotation ratio is a functional ratio. When a bowler delivers the ball, the internal rotators are concentrically contracted in order to accelerate the arm. In order to decelerate the arm after ball release the external rotators are contracted eccentrically. To achieve high ball delivery speeds the external eccentric forces must be great enough to balance these concentric and eccentric contractions, with a relationship between dysfunction and injury. ${ }^{2,7,8,18}$ Sixteen of the 21 fast bowlers showed low stability ratios (Table III), compared with gravity corrected functional ratios of between $117 \mathrm{Nm}$ and $160 \mathrm{Nm},{ }^{12}$ indicating an imbalance and the presence of possible dysfunction. Further, the concentric external-internal rotation also indi- 
cates a muscle imbalance at both speeds possibly predisposing these players to injury or re-injury due to previous chronic shoulder injuries that may not have been fully rehabilitated.

Athletes with impingement syndrome show a high degree of hypermobility in the anterior capsule of the shoulder, with excessive external rotation ROM and general ligament laxity of the glenohumeral joint. These are contributory factors to developing impingement. ${ }^{20}$ The shoulder hypermobility of these groups of fast bowlers, as indicated by an increase in external rotation of the shoulder, may be a risk factor in the development of an impingement injury. The demands placed on the shoulder of a fast bowler are great and any muscle imbalances in the shoulder region could result in injury or reinjury. The difference between the uninjured and injured groups in the concentric internal rotation peak torque/body weight at $180^{\circ} . \mathrm{s}^{-1}$ indicates muscle imbalance in the rotator cuff muscles, which combined with a fast delivery speed with a front-on bowling action, may be a predisposing factor for shoulder injuries in cricket fast bowlers. Although no significant differences were found between the injured and uninjured subjects, the results indicate that imbalance in the rotator cuff muscles, combined with a front-on bowling action, may be a predisposing factor for impingement syndrome in cricket fast bowlers. Thus, bowler, coaches and fitness trainers need to ensure that fast bowlers follow a specific shoulder strengthening and flexibility programme to reduce the risk of injury. Further, the personnel involved with the rehabilitation of the player after a shoulder injury need to continually assess the strength and flexibility of the shoulder and the ratios between the strength of agonist and antagonist muscle groups. Only when fully recovered should a player be allowed to return to match play otherwise the player runs the risk of re-injury and a shortened career with further shoulder problems.

\section{REFERENCES}

1. Anderson MK, Hall SJ, Martin M. Sports Injury Management. 2nd ed. Philadelphia: Lippincott Williams \& Wilkins, 2000.

2. Brown L. Isokinetics in Human Performance. Champaign, IL: Human Kinetics, 2000.

3. Brukner P, Khan K. Clinical Sports Medicine. Sydney: McGraw-Hill, 1993.

4. Codine P, Bernard PL, Pocholle M, Benaim C, Brun V. Influence of sports discipline on shoulder rotator cuff balance. Med Sci Sports Exerc 1997; 29:1400-5

5. Crisp TA. Cricket injuries. Sports Therapy 1990; 1(1):22-3.

6. Davis K, Blanksby B. The segmental components of fast bowling in cricket. Australian Journal for Health, Physical Educationand Recreation 1976; 71: suppl, 6 - 8.

7. Donatelli RA, Ellenbecker T, Ekedahl S, Wilkes JS, Kocher PT, Adam J. Assessment of shoulder strength in professional baseball pithcers, $J$ Orthop Sports Phys Ther 2000; 30: 544-51.

8. Dvir Z. Isokinetics: Muscle Testing, Interpretation and Clinical Applications. Edinburgh: Churchill-Livingstone, 2000.

9. Elliott BC, Foster DH. A biomechanical analysis of the front-on and sideon bowling techniques. Journal of Human Movement Studies 1984; 10: 83 - 94.

10. Foster D. Injury and prevention in fast bowling. Proceedings of the Australian Sports Medicine Federation Annual Scientific Conference, Perth, Australia, 1984.

11. Gore CJ. Physical Tests for Elite Athletes. Australian Sports Commission. Champaign, IL: Human Kinetics, 2000.

12. Guillermo J. Isokinetic eccentric-to-concentric strength ratios of the shoulder rotator muscles in throwers and nonthrowers. Am J Sports Med 2003; 10: 537 - 41

13. Hall SJ. Basic Biomechanics. 3rd ed. Boston: McGraw-Hill, 1999.

14. Heyward VH. Advanced Fitness Assessment and Exercise Prescription. 3rd ed. Champaign, IL: Human Kinetics, 1997

15. King GA. Internal and external shoulder rotator strength of cricketers vs. non-cricketers: An isokinetic comparison. Masters thesis, Rhodes University, Grahamstown, South Africa, 1997.

16. Luttgens K, Deutsch H, Hamilton N. Kinesiology: Scientific Basis of Human Motion. 8th ed. Madison, Wisconsin: Brown and Benchmark, 1992.

17. Newsham KR, Keith CS, Saunders JE, Gaffinett AS. Isokinetic profile of baseball pitchers' internal and external rotation $180,300,450^{\circ} . \mathrm{s}^{-1}$, Med Sci Sports Exerc 1998; 30: 1489-95.

18. Perrin DH. Isokinetic Exercise and Assessment. Champaign, IL: Human Kinetics, 1993.

19. Stretch RA. The incidence and nature of injuries in schoolboy cricketers. S Afr Med J, 1995; 85: 1182-4.

20. Wilk KE, Arrigo C. Current concepts in the rehabilitation of the athletic shoulder. J Orthop Sports Phys Ther 1993; 18: 365. 